\title{
NUISANCE PSYCHODA ALTERNATA (DIPTERA: PSYCHODIDAE) DEVELOPING IN POTTED PLANTS AT A COMMERCIAL NURSERY
}

\author{
MATTEO PALLOTTINI', C. LEE BLOOMCAMP², ROBERTO M. PEREIRA ${ }^{3 *}$, \\ AND PHILIP G. KOEHLER ${ }^{3}$ \\ 'Department of Chemistry, Biology and Biotechnology, University of \\ Perugia, Via Elce di Sotto 8, 06132 Perugia (PG), Italy \\ E-mail: matteo.pallottini@unipg.it
}
${ }^{2}$ Syngenta Professional Solutions, 8518 SW 98th Ave., Gainesville FL 32608 E-mail: lee.bloomcamp@syngenta.com

\author{
${ }^{3}$ Entomology and Nematology Department, University of Florida, \\ 1881 Natural Area Dr., Gainesville, FL 32611 \\ E-mail: rpereira@ufl.edu,pgk@ufl.edu.
}

*Corresponding Author: Roberto M. Pereira

E-mail: rpereira@ufl.edu

Subiect Editor: Derrick Mathias

\begin{abstract}
Moth flies (Psychoda alternata Say) were reported emerging in large numbers from potted plants at a commercial nursery near Fort White, Columbia County, FL and causing an annoyance and potentially a public health nuisance at neighboring residences. The distribution of its fly immature stages in the soil of recently re-potted plants was investigated. Two species of plants from the commercial nursery were selected, soil samples were taken at different depths and positions and each soil sample was extracted using a technique for nematode extraction from soil. Larvae and pupae of $P$. alternata moth flies were identified in the samples. Psychoda alternata is commonly found breeding in trickling filters and this is the first record of it being an important nuisance pest in newly potted plants.

Key Words: drain fly; trickling filter fly; nuisance; soil
\end{abstract}

Several species of flies are known to be nuisance pests at commercial nurseries and greenhouses (Tilley et al. 2011; Cloyd 2015), however, Psychoda alternata Say (Psychodidae, Psychodinae) have not been reported as a pest problem in potted plants. Recently, moth flies were reported to be emerging in large numbers from potted plants at a commercial nursery near Fort White, Columbia County, Florida causing annoyance and potential health problems for neighboring homeowners.

Psychoda alternata is usually called "drain fly", due to its tendency to live and reproduce in shallow and polluted water (El Bardicy et al. 2009), or "trickling filter fly" because it is commonly found breeding in trickling filters (Fair 1934). The adults are dark grey, 2.5 to $4.5 \mathrm{~mm}$ long, the body and the wings are characterized by a dense covering of long hair and leaf-shaped wings which are held roof-like over the body (Fair 1934; El Bardicy et al. 2009; Yones et al. 2014). Psychoda alternata do not bite, but they can represent a real problem when emerging in enormous numbers. The flies can be carried by the wind up to one mile and penetrate through the window screens of nearby structures (Headlee 1919; Fair 1934; den Otter 1966; El Bardicy et al. 2009) causing nuisance and public health concerns. Asthma caused by $P$. alternata has been reported in many parts of the world (Ordman 1946; den Otter 1966; Phanichyakarn et al. 1969; 
Gold et al. 1985). Cases of urogenital myiasis caused by $P$. alternata have been related to poor human hygienic conditions (den Otter 1966; Hira et al. 1997; Yones et al. 2014; Saadawi et al. 2017), and ocular myiasis has also occurred (Kamimura 1967). Psychoda alterna$t a$ is also known to be forensically significant, and recently was identified in human cadavers (Lindgren et al. 2015). Therefore, P. alternata has the potential to be a significant public health problem for residences near commercial nurseries.

The County Health Department, Florida Department of Agriculture and Consumer Services, and Mosquito Control District were contacted by the affected homeowners to investigate the problem. A large commercial nursery bordered the affected houses and no other sources of these moth flies were located in this rural area. The nursery owner observed that 10-14 days after re-potting new plants large numbers of 2-4 mm sized moth flies would be seen on the foliage of some plants. An inspection of the ground under pots placed on a weed barrier indicated no larvae.

The main objective was to determine whether moth flies were developing in plant pots at this commercial nursery and to determine the distribution of immature moth fly stages in the media of recently re-potted plant species that were observed to have adult flies associated with their vegetation.

Two species of recently re-potted plants from the commercial nursery were selected. Camellia (Camellia japonica) were propagated at the same nursery and then re-potted in 26.5-liter pots 7 days before collection. Gardenia (Gardenia jasminoides) were purchased from another nursery as small plants and then re-potted in 26.5-liter pots 14 days before collection. Three containers for each of the two species were returned to the laboratory for analysis during March 2019.

The soil used for re-potting all plants was composed of $55 \%$ pine bark $(1.3 \mathrm{~cm}), 25 \%$ pine bark $(2.2 \mathrm{~cm})$, and $20 \%$ Canadian peat. Additives to the media mix were fertilizer $\left(7.12 \mathrm{~kg} / \mathrm{m}^{3}\right.$ Nutricote, Arysta Life Science, Cary, NC), iron humate $\left(5.93 \mathrm{~kg} / \mathrm{m}^{3}\right)$, dolomite $\left(2.67 \mathrm{~kg} / \mathrm{m}^{3}\right)$, and synthetic gypsum $100\left(1.48 \mathrm{~kg} / \mathrm{m}^{3}\right)$. Bifenthrin granules $(1.78$ $\mathrm{kg} / \mathrm{m}^{3}$ ) were added to the potting media to comply with the USDA imported fire ant quarantine (APHIS 2018). The plants were irrigated twice per week, as needed, to wet the medium to the bottom of the pot, without runoff.

Twelve samples $(150 \mathrm{ml}$ each $)$ of media were collected the day after bringing the plants to the laboratory. Samples were taken at 8-days after re-potting (DARP) for Camellia and 15-DARP for Gardenia. To establish the distribution of insect larvae and pupae in the potting medium surrounding the roots of potted plants, twelve media samples were removed from each pot at 5 -cm increments from the surface $(0-5 \mathrm{~cm})$ to the bottom $(25-30 \mathrm{~cm})$. Six samples were from the perimeter of the medium, and six were from the center. There were 72 samples total with 36 for 8-DARP Camellia and 36 for 15-DARP Gardenia.

Samples were examined using a technique commonly applied for nematode extraction from soil. This technique was tested prior to use in the experiment and produced good results in the extraction of small fly larvae from soil. This technique may be useful for extraction and quantification of other small insect larvae from soil samples. Each 150-ml sample was washed thoroughly into a sieve (2-mm mesh) to remove the bigger fraction of the media followed by passing media through a smaller sieve $(37-\mu \mathrm{m}$ mesh). The smaller fraction was transferred into a $100-\mathrm{ml}$ centrifuge tube and centrifuged for $5 \mathrm{~min}$ at $3500 \mathrm{rpm}$. The supernatant was removed, and sugar solution (454 g sucrose/liter of water) was added to the remaining sample and recentrifuged for $5 \mathrm{~min}$ at $3500 \mathrm{rpm}$. At this stage, the supernatant was filtered through a 25- $\mu \mathrm{m}$ mesh sieve and transferred into 50$\mathrm{ml}$ tubes. The collected material was preserved in $70 \%$ isopropyl alcohol and examined under a stereo microscope to identify and count fly larvae and pupae. Taxonomic keys by Quate (1955) were used.

The effects of depth and position (periphery or center) on the distribution of moth fly larvae and pupae were analyzed us- 
ing a two-way ANOVA, and means were compared using Student's t-test $(\mathrm{P}<0.05)$ in JMP Statistical Analysis Software (SAS Institute, Cary, North Carolina, USA). Before analysis, data were transformed using square-root transformation to normalize the data distribution.
Four hundred and fourty-four larvae and pupae of Psychoda alternata were found in the samples (Figure 1). Psychoda alternata totaled $60 \%$ of all insect pupae in all samples, $56 \%$ of the insect pupae in 8-DARP Camellia, and $81 \%$ of the pupae in 15-DARP Gardenia. Only mature larvae were found in the
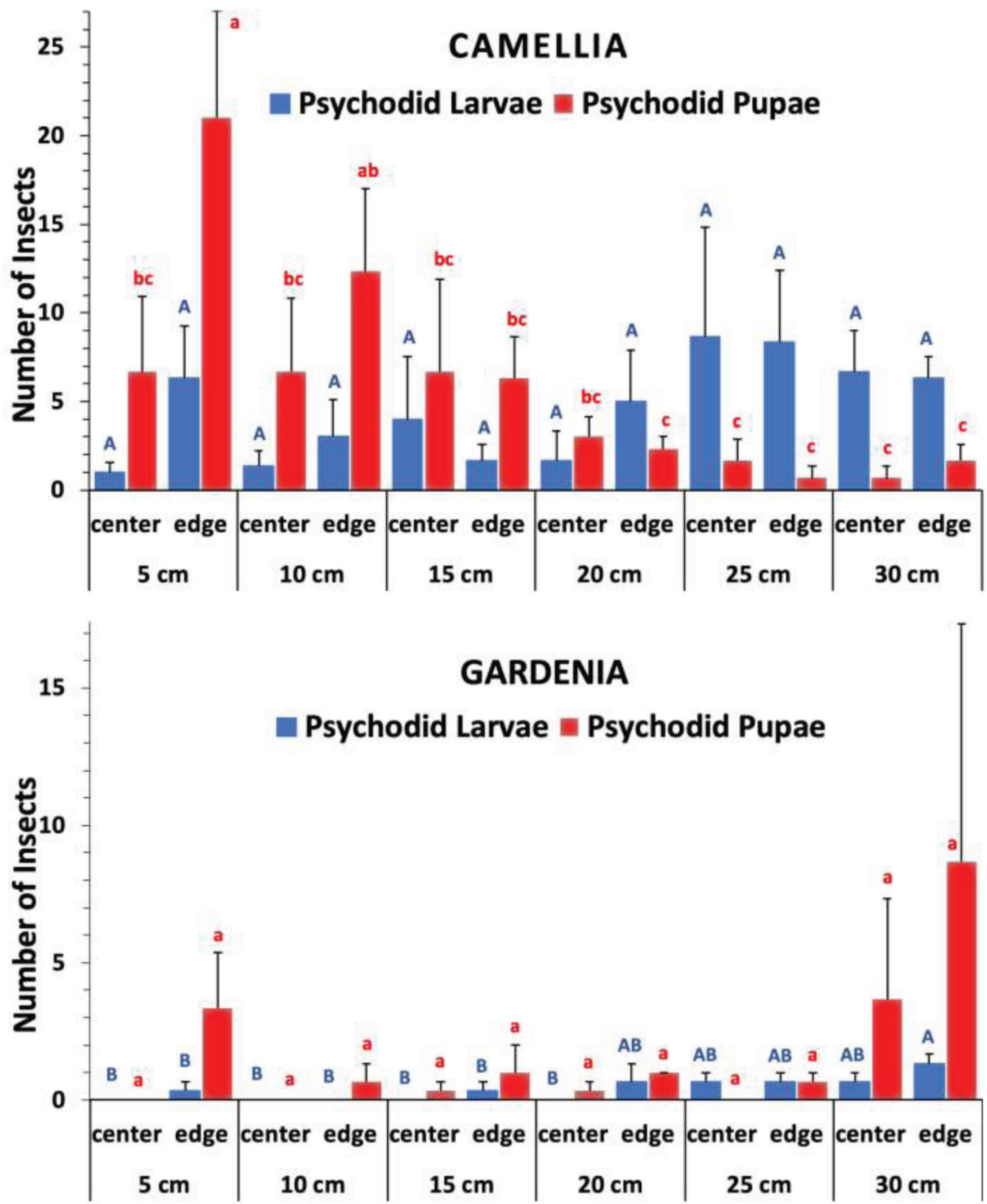

Figure 1. Distribution (mean +/- std. error) of Psychoda alternata larvae and pupae at 5 to $30 \mathrm{~cm}$ depth in (top) 8-DARP Gardenia and (bottom) 15-DARP Camellia pots at a commercial nursery near Fort White, Columbia County, Florida in March 2019. 
samples. Considering the duration of the life cycle and the short time of the pupal period (20-40 h, El Bardicy et al. 2009), egg deposition may have occurred soon after re-potting, with only one generation occurring inside the pots without an overlapping generation. In other studies in which populations of $P$. alternata were stable with overlapping generations (Ali et al. 1991, Ali and Kok-Yokomi 1991), pupae were found in low percentages, between 8 and 23\%, due to the short duration of the pupal stage.

In 8-DARP Camellia (Figure 1, top), number of $P$. alternata larvae $(\mathrm{F}=1.60 ; \mathrm{p}=0.20)$ were not associated with layer depth in the pots while pupae were more abundant in the first three layers $(0-15 \mathrm{~cm})(\mathrm{F}=5.11 ; \mathrm{p}=$ 0.003), with a significant difference in relation to deeper layers. In 15-DARP Gardenia (Fig 1, bottom), pupae were not associated with depth $(\mathrm{F}=1.00 ; \mathrm{p}=0.44)$, while larvae were more abundant $(\mathrm{F}=3.37 ; \mathrm{p}=0.02)$ deeper in the pot soil, with a significant difference in relation to the upper layers, although the overall larval abundance was very low compared to the numbers of $P$. alternata pupae.

In 8-DARP Camellia, pupae were significantly more abundant $(\mathrm{F}=6.27 ; \mathrm{p}=0.02)$ in the exterior perimeter of the potting soil compared with the central area of the pots, whereas larvae were found in similar numbers at the perimeter and the central area of the pots $(\mathrm{F}=2.23, \mathrm{p}=0.15)$. In 15-DARP Gardenia, both larvae $(\mathrm{F}=1.00 ; \mathrm{p}=0.44)$ and pupae $(\mathrm{F}=1.86 ; \mathrm{p}=0.19)$ were uniformly dispersed in the media, showing no preference for either the perimeter or central area of the pots.

Psychoda alternata has not been previously reported as an important nuisance pest in newly potted plants. For both species of sampled plants, the potting medium was identical, and provided all the necessary requirements for $P$. alternata development regardless of plant species. Moreover, the bifenthrin treatment applied to the potting medium, as part of the fire ant quarantine protocol to prevent establishment and movement of fire ant colonies, was ineffective for control of the $P$. alternata, potentially indicating some level of pesticide resistance in this insect population.
In order to complete its development, $P$. alternata needs high relative humidity, oxygen, decaying organic material and microorganisms for larval development, locations for pupation, and for the imagoes to hatch (den Otter 1966; El Bardicy et al. 2009). Psychoda alternata is a principal member of the invertebrate grazing fauna community which inhabits the biological filters of sewage treatment plants (Learner 2000), but it can inhabit other environments with decaying organic material and sufficient moisture (Haseman 1907; Turner 1925; Saunders 1928; Redborg et al. 1983). Ali and Kok-Yokomi (1991) and Ali et al. (1991) reported massive emergences of the species at a turf cultivation facility in Florida, where nutrient-rich wastewater was used for irrigation. In addition to these other locations, $P$. alternata has the potential to be a significant problem in commercial nurseries, although it appears to be a pest in the newly-placed media of re-potted plants, completing only one generation per pot.

Due to the nursery industry practices of replotting plants, the potential synchronous emergence of very high populations of these flies may represent a problem that mosquito control districts may be called upon to resolve and remediate. Additionally, if large populations of these flies move through densely populated areas, this may represent a potential health problem, especially for the elderly and other vulnerable segments of the population.

\section{REFERENCES CITED}

Ali A, Kok-Yokomi ML, Alexander JB. 1991. Vertical distribution of Psychoda alternata (Diptera: Psychodidae) in soil receiving wastewater utilized for turf cultivation. JAm Mosq Control Assoc 7: 287-289.

Ali A, Kok-Yokomi ML. 1991. Preliminary population assessment of Psychoda alternata (Diptera: Psychodidae) in soil irrigated with wastewater for turf cultivation. Fla Entomol 74: 591-596.

APHIS. 2018. Labels Available for Use in IFA Quarantine (March 2018). [Internet]Available from United States Department of Agriculture - Animal and Plant Health Inspection Service [accessed April 25, 2019]. https://www.aphis.usda.gov/plant_health/plant_ pest_info/fireants/downloads/IFA_QuarantineLables.pdf.

Cloyd RA. 2015. Ecology of fungus gnats (Bradysia spp.) in greenhouse production systems associated 
with disease-interactions and alternative management strategies. Insects 6: 325-332. doi: 10.3390/insects6020325.

den Otter CJ. 1966. A physical method for permanent control of Psychoda pests at wastewater treatment plants. I Water Pollut Control Fed 38(2): 156-164.

El Bardicy S, Tadros M, Yousif F, Hafez S. 2009. Predatory activity of Psychoda alternata Say (Diptera: Psychodidae) larvae on Biomphalaria glabrata and Lymnaea natalensis snails and the free-living larval stages of Schistosoma mansoni. Aust J Basic Appl Sci 3: 4503-4509.

Fair GM. 1934. The trickling filter fly (Psychoda alternata), its habits and control. Sewage Work J6: 966-981.

Gold BL, Mathews KP, Burge HA. 1985. Occupational asthma caused by sewer flies. Am Rev Respir Dis 131: 949-952. doi: 10.1164/arrd.1985.131.6.949.

Haseman L. 1907. A monograph of the North American Psychodidae, including ten new species of an aquatic psychodid from Florida. T Am Entomol Soc 33: 299-333.

Headlee TJ. 1919. Practical application of the methods recently discovered for the control of the sprinkling sewage filter fly (Psychoda alternata). J Econ Entomol 12: 35-41.

Hira PR, Hall MJR, Hajj B, Al-Ali F, Farooq R, Muzairai IA. 1997. Human myiasis in Kuwait due to Oestrus ovis, Psychoda species and Megaselia species. Med Princ Pract 6: 129-136. doi: 10.1159/000157540.

Kamimura K. 1967. A case of human ocular myiasis due to the moth fly, Psychoda alternata. Med Entomol Zool 18: 305-306. doi: 10.7601/mez.18.305.

Learner MA. 2000. Egression of flies from sewage filterbeds. Water Res 34: 877-889. doi: 10.1016/S00431354(99)00190-6.

Lindgren NK, Sisson MS, Archambeault AD, Rahlwes BC, Willett JR, Bucheli SR. 2015. Four forensic en- tomology case studies: records and behavioral observations on seldom reported cadaver fauna with notes on relevant previous occurrences and ecology. J Med Entomol 52: 143-150. doi: 10.1093/jme/tju023.

Ordman D. 1946. Bronchial asthma caused by the trickling sewage filter fly (Psychoda): inhalant insect allergy. Nature 157: 441.

Phanichyakarn P, Dockhorn RJ, Kirkpatrick CH. 1969. Asthma due to inhalation of moth flies (Psychoda). J Allerg 44: 51-58.

Quate LW. 1955. A revision of the Psychodidae (Diptera) in America north of Mexico. Univ Calif Publ Entomol 10: 103-273.

Redborg KE, Hinesly TD, Ziegler EL. 1983. Rearing Psychoda alternata (Diptera: Psychodidae) in the laboratory on digested sewage sludge, with some observations on its biology. Environ Entomol 12: 412-415.

Saadawi WK, Shaibi T, Annajar BB. 2017. A human case of urogenital myiasis caused by Psychoda sp. larvae in Tripoli, Libya. Ann Parasitol 63: 69-71. doi: 10.17420/ap6301.88.

Saunders LG. 1928. Psychoda alternata Say breeding in the sea. Entomologist 61: 209.

Tilley LAN, Croft P, Mayhew PJ. 2011. Control of a glasshouse pest through the conservation of its natural enemies? An evaluation of apparently naturally controlled shore fly populations. Biol Control 56: 22-29. doi: 10.1016/j.biocontrol.2010.09.003.

Turner CL. 1925. The Psychodidae (moth-like flies) as subjects for studies in breeding and heredity. Am Nat 57: 545-549.

Yones DA, Bakir HY, Hameed DA. 2014. Human Urogenital Myiasis Caused by Psychoda Species Larvae: Report of Five Cases and Morphological Studies. J Adv Parasitol. 1: 12-20. doi: 10.14737/journal. jap/2014/1.2.12.20 